\title{
Processing of an AA7050/Al Hybrid Composites Reinforced with Multiwalled Carbon Nanotubes
}

\author{
Luana A. Batista, ${ }^{a,}$ (D), Thiago H. R. da Cunha ${ }^{b}$, Marcos D. V. Felisberto ${ }^{b}$, Paulo R. Cetlin ${ }^{c}$ (D), \\ Eric M. Mazzer ${ }^{a}$ (1) \\ ${ }^{a}$ Universidade Federal de Minas Gerais (UFMG), Departamento de Engenharia Metalúrgica e de \\ Materiais (DEMET), Belo Horizonte, MG, Brasil. \\ ${ }^{b}$ Parque Tecnológico de Belo Horizonte, Centro de Tecnologia em Nanomateriais e Grafeno (CTNano), \\ Belo Horizonte, $M G$, Brasil. \\ ${ }^{c}$ Universidade Federal de Minas Gerais (UFMG), Departamento de Engenharia Mecânica (DEMEC), \\ Belo Horizonte, MG, Brasil.
}

Received: February 04, 2021; Revised: May 21, 2021; Accepted: July 05, 2021

\begin{abstract}
The development of carbon nanotubes reinforced metal matrix composites merits relevant attention due to its capacity of improve the hardness and strength of the metal. However, the production of this kind of composite presents many challenges, such as the dispersion and adhesion of carbon nanotubes in the metallic matrix, wich may affect the composite consolidation. The present study aimed the development of composites using an age hardening aluminum alloy reinforced with 0.5 wt. $\%$ of multiwalled carbon nanotubes (MWCNT) as well as a hybrid composite based on the mixture of pure aluminum powder and the former composite. AA7050 alloy and pure aluminum matrix composites were processed by ultrasonic mixing, hot pressing and hot extrusion. Subsequently, the materials were submitted to aging heat treatments. The samples were analysed by Scanning Electron Microscopy, X-Ray Diffraction, Atomic Force Spectroscopy, Raman spectroscopy, and Vickers microhardness. It was verified the feasibility in manufacturing the composites by the powder metallurgy route proposed in this work. The AA7050 composite reinforced with 0.5 wt.\% MWCNT presented higher hardness than other similar composites in the literature with higher carbon nanotubes content. The aged composite hardness increased $72 \%$ in comparison with the present one in the as extruded condition.
\end{abstract}

Keywords: Metal matrix composites, Carbon nanotubes, Aluminum composite, Hybrid composite, Al/CNT composite, Powder metallurgy.

\section{Introduction}

The development of lightweight metal composites, such as carbon nanotubes reinforced aluminum matrix (CNT/ $\mathrm{Al}$ ), allows changes in properties of the pure metal or alloy without adding weight. Several investigations show an improvement in the mechanical properties of pure Al by incorporating carbon nanotubes $(\mathrm{CNT})^{1-4}$. According to the data evaluated by Jagannatham et al. ${ }^{5}$, about $70 \%$ of the papers published in CNT/Al composites have pure Al as matrix and $30 \%$ have Al alloys as a matrix, due to low cost and easier processing of pure $\mathrm{Al}$.

To date, there have been only a few studies on CNT/Al alloy composites involving aging heat treatments. Different reports indicate that carbon nanotubes increase the strength ${ }^{6-8}$, and also affect the precipitation kinetics ${ }^{9-11}$ in age hardenable alloys. Also, the improvement of other properties such as electrical and thermal conductivity ${ }^{12-15}$.

Uriza-Vega et al. ${ }^{6}$ have prepared AA7075 composites reinforced with amounts between 0 and 3 wt.\% of CNT. The materials were processed by mechanical milling, cold

*e-mail: luana.araujob2@gmail.com pressing, sintering, and hot extrusion. Despite of AA7075 being an age-hardenable alloy, the authors have not aged the composites. The mechanical evaluation showed a tensile strength increment of $37 \%$ for the addition of $2.5 \mathrm{wt} . \%$ of multiwalled carbon nanotubes (MWCNT) in the milled metal powder. A similar trend was noticed for the hardness behavior of the composites couplet to a decrease in tensile elongation with the increment of CNT content.

Thomas and Umasankar ${ }^{10}$ studied the influence of CNT on the precipitation of an aged AA2219 alloy. They showed that the addition of $0.75 \mathrm{wt} . \%$ MWCNT resulted in a hardness peak after aging the material for 1,5 h, which corresponds to a $27 \%$ of improvement over the maximum hardness in the pure alloy after aging for $10 \mathrm{~h}$.

Most researches explore the effect of CNT in a single metallic matrix basically using one type of metal. A review of the literature reveals only a few papers involving hybrid metal matrix composites reinforced by $\mathrm{CNT}$ and with other ceramic reinforcements like $\mathrm{Al}_{2} \mathrm{O}_{3}{ }^{16,17}, \mathrm{SiC}^{18}$, and $\mathrm{TiC}^{19}$.

Morsi et al. ${ }^{20}$, Shin, Choi and $\mathrm{Bae}^{12}$, and Salama, Abbas and Esawi ${ }^{21}$ investigated the use of dual matrix designed composite using $\mathrm{CNT} / \mathrm{Al}$ powders as reinforcement in pure 
Al powders to improve the ductility of the composites. The results indicate benefits regarding their workability, making easier the composite consolidation ${ }^{20,21}$.

Shin, Choi and $\mathrm{Bae}^{12}$ produced CNT/Al composites with a final proportion of $2 \%$ MWCNTs by powder metallurgy. Two composites were processed by mixing 4 wt.\% CNT/ $\mathrm{Al}$ with $\mathrm{Al}$ in the ratio of 1:1 with different milling times, resulting in composites with different CNT dispersion and bonding with the matrix. The powders were put in a copper tube, degassed, sealed, heated to $480{ }^{\circ} \mathrm{C}$, and then hotrolled. They reported a threefold increase in the electrical conductivity of the composite processed at $100 \mathrm{rpm} / \mathrm{min}$ for $2 \mathrm{~h}$ as compared to the monolithic aluminum.

Salama, Abbas and Esawi ${ }^{21}$ prepared composites from milled CNT/Al powders (single matrix) and mixtures of pure $\mathrm{Al}$ and milled CNT/Al powders (dual matrix). The composites were consolidated by the same route: cold compaction, then sintering at $500{ }^{\circ} \mathrm{C}$ for $1 \mathrm{~h}$, and hot extrusion at $500{ }^{\circ} \mathrm{C}$. Composites with 1 wt.\% CNT presented strength $9.2 \%$ lower for the dual matrix composite (mixture ratio 1:1) than for the single matrix. Meanwhile, the ductility of the dual matrix was slightly improved by $10.7 \%$ compared to pure $\mathrm{Al}$.

Wei et al. ${ }^{22}$ compared two composites with 2 wt.\% CNT: a AA7055 powder reinforced by CNT and other composite involving the mixture of CNT/AA7055 powders with AA7055 metal powders in a proportion of 1:1 in a laminated structure. Both materials were processed by hot pressing $\left(600^{\circ} \mathrm{C}, 10 \mathrm{MPa}\right)$, and then hot extruded at $440{ }^{\circ} \mathrm{C}$. Then they were solution heat treated, quenched, and aged for $24 \mathrm{~h}$ at an unreported temperature. Between the studied samples, the best mechanical proprieties were observed in the composite blended with laminated particles, which presented an increase in yield strength of about $126 \mathrm{MPa}$ in relation to the composite with the AA7055 matrix.

It was not found in the literature a report covering a hybrid composite reinforced with carbon nanotubes and an aluminum alloy in a pure aluminum matrix. It is important to understand the feasibility of the processing of this type of composite in order to develop and improve new alloys or metallic composites. Therefore, the present work evaluated two types of composites. The first consists in 0.5 wt.\% multiwalled carbon nanotubes with AA7050 aluminum alloy as a matrix. The second is based on pure aluminum as a matrix with the addition of $20 \%$ in weight of the former composite powder. The purpose of creating a new composite with $\mathrm{Al}$ reinforced with another composite is to verify the possibility of obtaining a composite with better workability. In addition, a new fabrication route based in powder metallurgy is proposed for a simple and viable consolidation process.

\section{Material and Methods}

MWCNT were produced by chemical vapor deposition, and they were functionalized by adding $-\mathrm{OH}$ and $-\mathrm{COOH}$ groups in the external surfaces. The functionalization degree obtained by thermogravimetric analysis (TGA) was around $8 \mathrm{wt} \%$, as reported in our previous work ${ }^{23}$. AA7050 powders $(4.06 \% \mathrm{Zn}, 2.37 \% \mathrm{Mg}, 2.29 \% \mathrm{Cu}, 0.57 \% \mathrm{Fe}$ and Al balance) with granulometry in the range of 45 to $80 \mu \mathrm{m}$ were used in this study. The powders were produced by spray forming technique, according to the procedure described by Mazzer et al. ${ }^{24,25}$ using as raw material machining chips from the aeronautic industry. After the processing, the powders were sieved in the selected range. Then, the AA7050 powders were added to the nanotubes suspension ( $1 \%$ (wt./v) in ethanol) to obtain after solvent evaporation composites with the concentration of $0.5 \mathrm{wt} . \%$ of MWCNT (composite A). The metal powder and MWCNT suspension were homogenized in an ultrasonic bath for $10 \mathrm{~min}$. The solvents were then evaporated in a rotary evaporator for $30 \mathrm{~min}$ at $100^{\circ} \mathrm{C}$, and the final drying was performed in a drying oven at $180{ }^{\circ} \mathrm{C}$ for $1.5 \mathrm{~h}$. Comercially pure aluminum powders with $7 \mu \mathrm{m}$ (99.7\%, Alfa Aesar) were used for composite B, which is composed of a mixture of $80 \mathrm{wt} . \%$ of $\mathrm{Al}$ and $20 \mathrm{wt} . \%$ of composite A.

Both composites were submitted to the same consolidation conditions as schematized in Figure 1. The powders were hot compacted as cylinders of $13 \mathrm{~mm}$ in diameter in a hydraulic press at $13 \mathrm{Ton}(962 \mathrm{MPa})$ at $350^{\circ} \mathrm{C}$. Then, the billets were hot extruded to $5 \mathrm{~mm}$ in diameter at $350^{\circ} \mathrm{C}$. Age hardening treatments were applied to the composites. This aging heat treatment was carried out at the typical conditions for this alloy ${ }^{25,26}$ : solubilization at $470^{\circ} \mathrm{C}$ for $0.5 \mathrm{~h}$, cooling in ice water and artificial aging at $121^{\circ} \mathrm{C}$ for $24 \mathrm{~h}$.

The microstrucutural characterization of the composites was carried out using a scanning electron microscope (SEM). The chemical composition analysis were performed in regions of interest with THERMO NORAN X-Ray Dispersive Energy Spectroscopy (EDS) detector, Quest model installed on the SEM. The determination of crystalline phases was performed by X-Ray Diffraction (XRD) with $\mathrm{Cu} \mathrm{K} \alpha$ radiation (a)

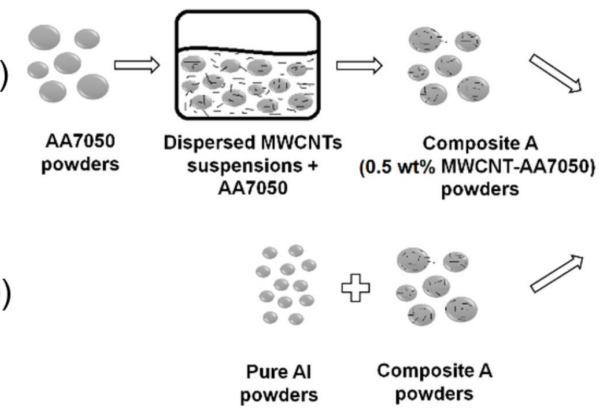

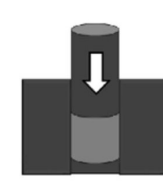

Hot compaction process
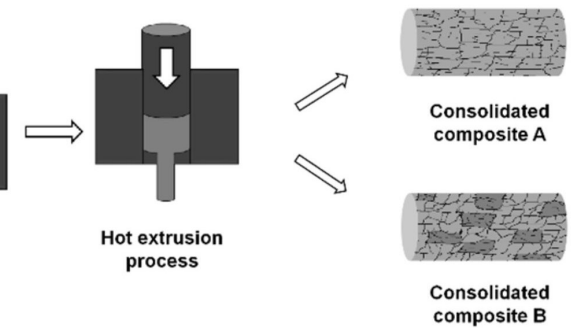

Figure 1. Representation of the powder metallurgy process of (a) composites A and (b) composite B. 
$(\lambda=1.5406 \AA)$, scanning angle $(2 \theta)$ from $20^{\circ}$ to $90^{\circ}$, step size of $0.02^{\circ} / \mathrm{s}$, and 1 -second count per pass were used.

The presence of MWCNT and their structural integrity in the composites was evaluated through Raman Spectroscopy with a Raman SENTERRA R200-L spectrometer with $\mathrm{Ar}^{+}$ laser source as an excitation source and $1064 \mathrm{~nm}$ line. An Atomic Force Microscope (Cypher ES Asylum Research) was also used with this purpose. The hardness of the materials were carried out in a Vickers microhardness equipment. The applied load was $3 \mathrm{~N}$ and time of $12 \mathrm{~s}$. Twenty measurements were taken for each sample.

\section{Results and Discussion}

Figures 2a, b depict MWCNT impregnated in AA7050 powders after ultrasonic bath and solvent evaporation. A well dispersed and homogeneous distribution of MWCNT can be seen in Figure 2a, and some clusters of MWCNT in Figure $2 b$. It was observed the occurrence of MWCNT in both forms, as well as heterogeneous distribution of MWCNT between different particles. A challenge in the fabrication of CNT-reinforcement composites is the dispersion of CNT on the powder surface. Carbon nanotubes tend to stick together into clusters due to the secondary van der Waals forces ${ }^{27,28}$, even after chemical and mechanical processing.

These MWCNTs agglomerates significantly impair the total consolidation of the material, being considered one of the biggest challenges in the fabrication of metal matrix composites with CNT. They inhibit the contact between the metallic powders, which disturbs the sintering driving force. MWCNT clusters are observed between AA7050 particles in dark regions in Figure 2c, shown in detail in Figure 2d. The average cluster size was about $2.75 \mu \mathrm{m}$ in diameter.

AFM analysis were carried out to confirm whether the dark regions in Figure 2 consist of MWCNT clusters confined between AA7050 particles or not. Normally in AFM it is commonly necessary to apply an electrical charge in the material, so the sample is electrically connected to the sample holder. However, in the present situation this was not necessary; since the samples display regions with accumulated electric load (light regions in Figure $3 \mathrm{a}$, corresponding to the dark regions in the previous SEM image). MWCNT clusters appear self-elevated in relation to the matrix and electrically charged, as shown in Figure 3a. These results reinforce that the dark regions observed by microscopy are MWCNT clusters.

The extruded composite A contains coarse precipitates within the AA7050 alloy particles (Figure 3b). Second phases, such as $\mathrm{Al}_{7} \mathrm{Cu}_{2} \mathrm{Fe}, \mathrm{Al}_{2} \mathrm{CuMg}$, and $\mathrm{Mg}_{32}(\mathrm{Al}, \mathrm{Zn})_{49}$ are common in AA7XXX alloys with as-cast microstructure ${ }^{25,29-31}$. The intermetallic compound $\mathrm{Al}_{7} \mathrm{Cu}_{2} \mathrm{Fe}$ remains after solubilization, as reported by other researchers ${ }^{25,31}$. During artificial aging, the metastable phase $\eta^{\prime}$ is formed, which exhibits the higher hardness. Exposition for some time at high temperatures transform this metastable phase into the stable phase $\eta$
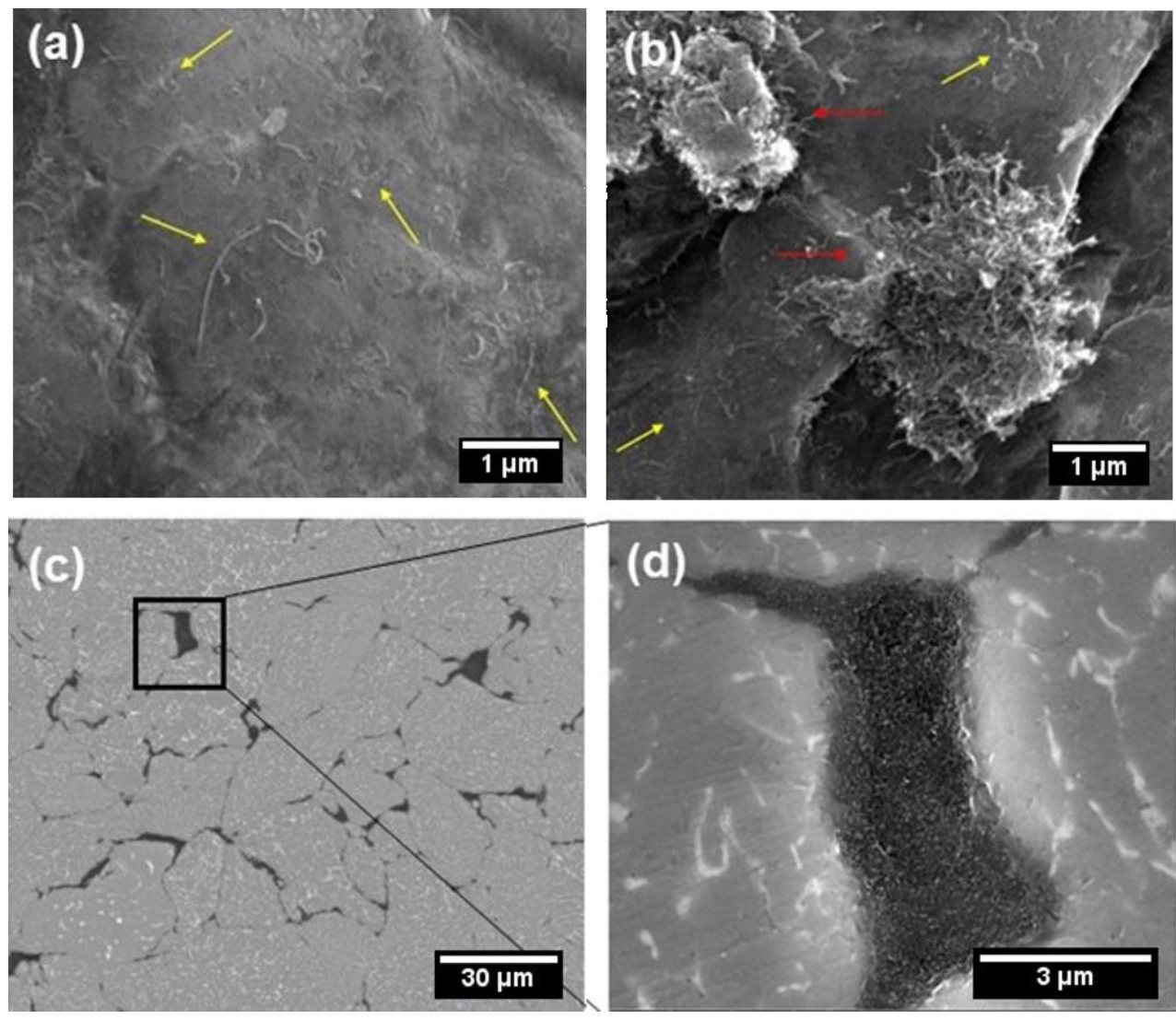

Figure 2. SEM images of Composite A (0.5 wt.\% MWCNT/AA7050): (a) powders with dispersed MWCNT (yellow arrows); (b) MWCNT clusters (red arrows); (c) hot extruded material; and (d) detail of a MWCNT cluster. 
(a)

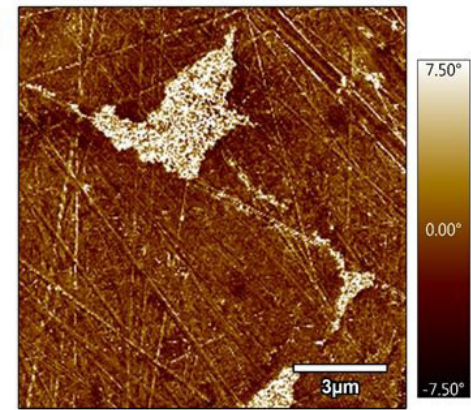

(c)

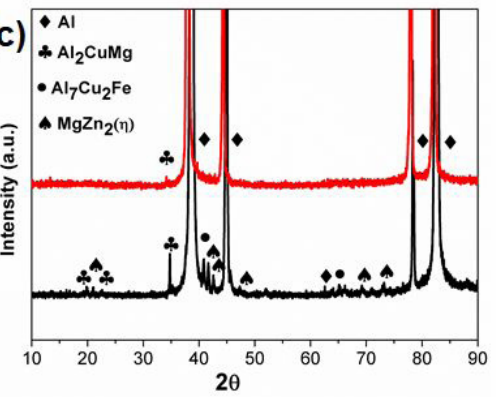

(b)

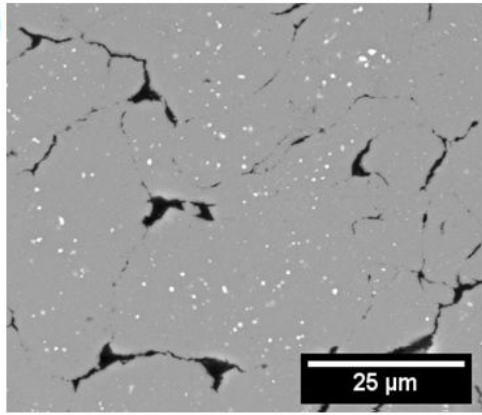

(d)

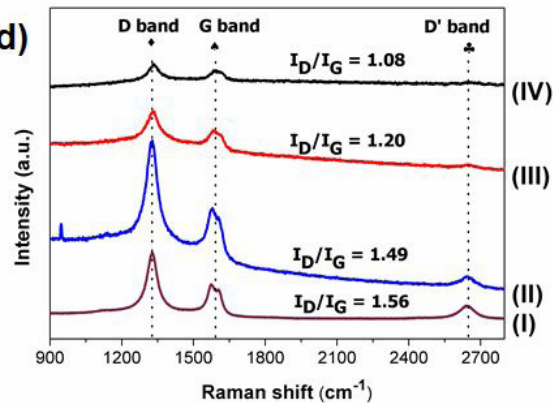

Figure 3. (a) Composite A phase images obtained by AFM; (b) SEM image of artificial aged sample; (c) XRD patterns of the hot extruded composite (I), (II) after artificial aging; and (d) Raman spectra of (I) composite powder, (II) hot extruded composite, (III) solubilized , and (IV) artificial aged composite.

$\left(\mathrm{MgZn}_{2}\right)^{7,25,31}$. This phase evolution also occurs in the composite alloy. It can be seen in XDR diffraction patterns (Figure 3c) of the aged sample that the highest peaks correspond to the FCC aluminum matrix. The main carbide's peaks were not observed in $2 \theta=26^{\circ 21}$, where they were supposed to have been diffracted. The $\eta$ ' and $\eta\left(\mathrm{MgZn}_{2}\right)$ hardening phases were evaluated together due to the overlapping of their XRD peaks $^{32}$. The nanometric size and low volume fraction of these precipitates result in small XRD peaks ${ }^{33}$. It should be noted that the coumpound $\mathrm{Al}_{4} \mathrm{C}_{3}$ was not identified in the difrractogram due to the absence of the main peaks for this phase (e.g. $2 \theta=31.5^{\circ}, 39.8^{\circ}$, and $54.7^{\circ}$ ).

Raman spectroscopy was performed to confirm the presence of MWCNT before and after the thermomechanical process. Figure $3 \mathrm{~d}$ shows the result of composite A in different conditions. The spectra are characterized by three substantial peaks corresponding typical D-band (disordered graphite, $1350 \mathrm{~cm}^{-1}$ ), G-band (graphite, $1572 \mathrm{~cm}^{-1}$ ), and D'-band with a peak around $2700 \mathrm{~cm}^{-1}$ which is the second order of the D peak ${ }^{34}$. The intensity ratio of the $\mathrm{I}_{\mathrm{D}} / \mathrm{I}_{\mathrm{G}}$ bands gives information about the crystallinity of the MWCNT. After the consolidation process, the value of $\mathrm{I}_{\mathrm{D}} / \mathrm{I}_{\mathrm{G}}$ had a small decrease, which can suggest some degradation of the structure of $\mathrm{MWCNT}^{8,35}$. In the present process, the stress and heat could have degraded a small amount of MWCNT.

In composite $\mathrm{A}$, the $\mathrm{CNTs}$ are on the surface of AA7050 powders. After the consolidation process, a direct contact of MWCNT - MWCNT with the neighboring particles is established causing the build-up of clusters between metal powders. These facts can limit the sintering of AA7050 particles, which makes consolidation less efficient. The novelty of the composite $\mathrm{B}$ is based on the premise that softer Al powders can work as building blocks surrounding particles of composite A. This provides a possible coverage of the exposed MWCNT. Thus, it reduces the direct contact of carbon nanotubes with each other, and promotes a beneficial pathway for better consolidation. This approach of covering exposed MWCNT with geometric confinement of composite particles was also applied to improve the consolidation by Wei et al. ${ }^{22}$, and Shin et al. ${ }^{12}$.

Figure 4 shows images of composite B after hot extrusion. The particles of composite A within composite B are dispersed in the Al matrix. Composite A particles have a light grey colour and present second phases (in white colour) with a similar aspect of that verified in the pure extruded one. The Al matrix is well consolidated with no open pores. Dark regions around the composite A particles are MWCNT clusters confirmed by EDS. These clusters are present only in small regions of some particles. They are indicated by yellow arrows in Figure 4b. Also, the micrograph displays aluminum oxide in the Al matrix (white arrows) analysed by EDS.

Figures 5a, b depict images of composite B extruded microstructure after solubilization heat treatment. The particles of composite A were outlined with a black line to facilitate their identification in Figure 5a, c. Most of the second phases of AA7050 alloy have been solubilized. Unexpectedly, the presence of many fine precipitates dispersed throughout the Al matrix (Figure 5b) was observed. EDS analysis indicates that these are composed by $\mathrm{Fe}$ and $\mathrm{Zn}$. A decrease of these elements in the AA7050 particles was also observed, as shown in Table 1. The Fe dispersions could have been 
derived from the contaminations in the pure raw material. In the aged samples of the extruded composite B, small precipitates on the Al matrix and AA7050 are also visible, as shown in Figure 5d.
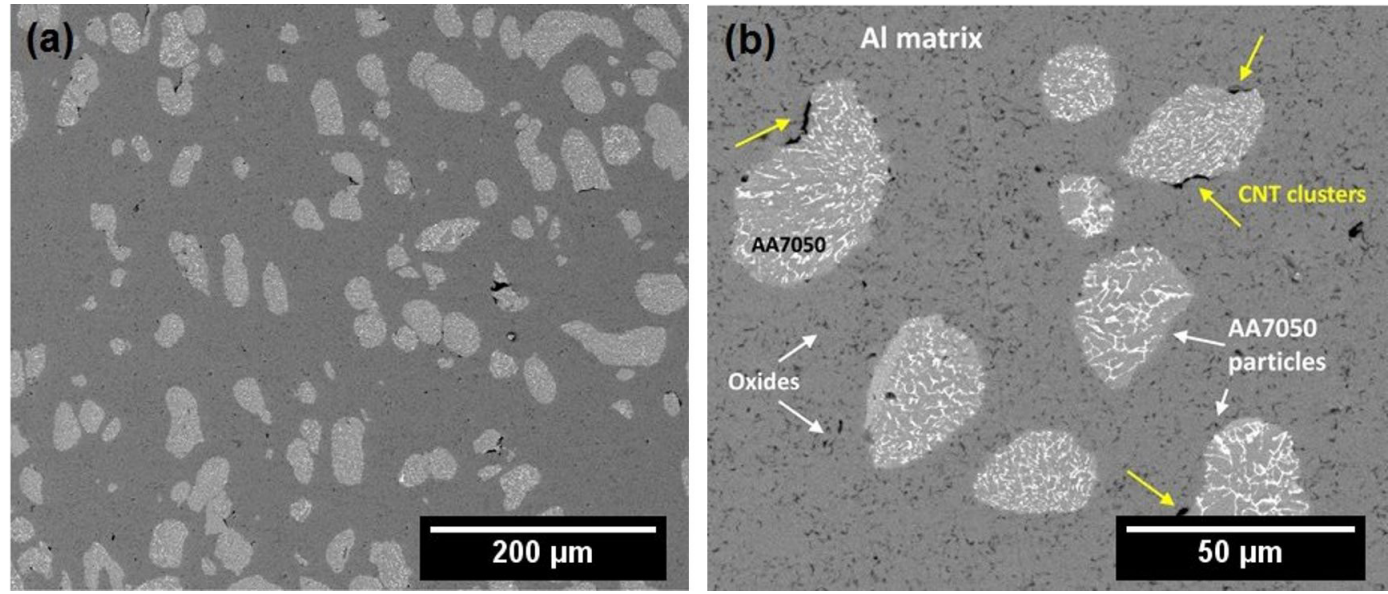

Figure 4. SEM images of composite $\mathrm{B}$ as extruded with (a) small and (b) large magnification. White arrows indicate $\mathrm{Al}$ oxide in the $\mathrm{Al}$ matrix and yellow arrows are MWCNT clusters.
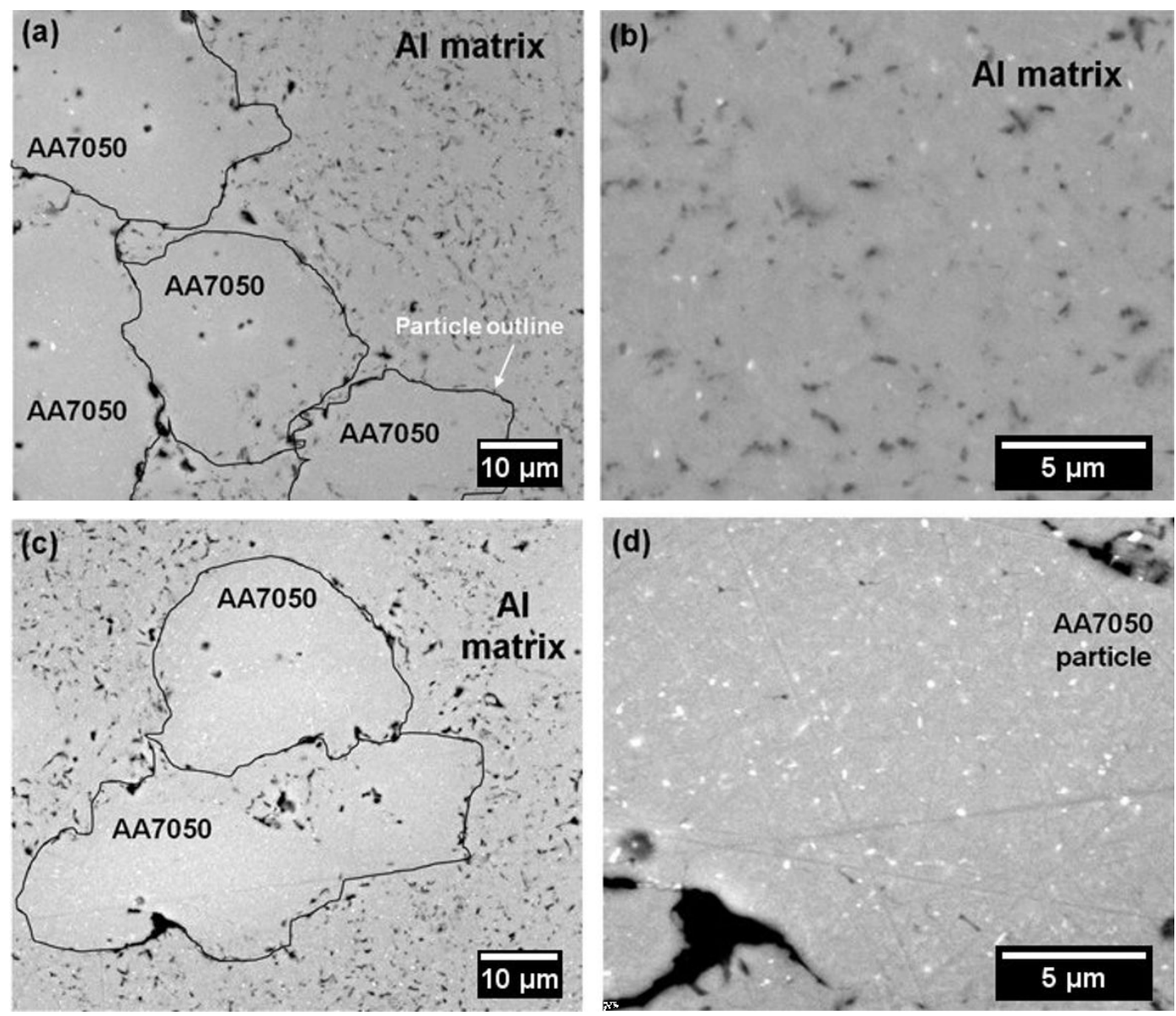

Figure 5. Hot extruded Composite B (a, b) after solubilization treatment images focusing on the precipitates in the Al matrix, and, (c, d) after aging treatment images focusing on the precipitates of AA7050. 
Table 1. EDS values of AA7050 particles in the Al matrix of composite B.

\begin{tabular}{lccccc}
\hline \multicolumn{1}{c}{ Condition } & $\mathrm{Al}$ & $\mathrm{Mg}$ & $\mathrm{Fe}$ & $\mathrm{Cu}$ & $\mathrm{Zn}$ \\
\hline Extruded & 89.53 & 2.59 & 0.46 & 2.77 & 4.65 \\
\hline Solubilized & 90.71 & 2.37 & 0.57 & 2.29 & 4.06 \\
\hline Aged & 95.06 & 1.58 & 0.33 & 0.79 & 1.39 \\
\hline
\end{tabular}
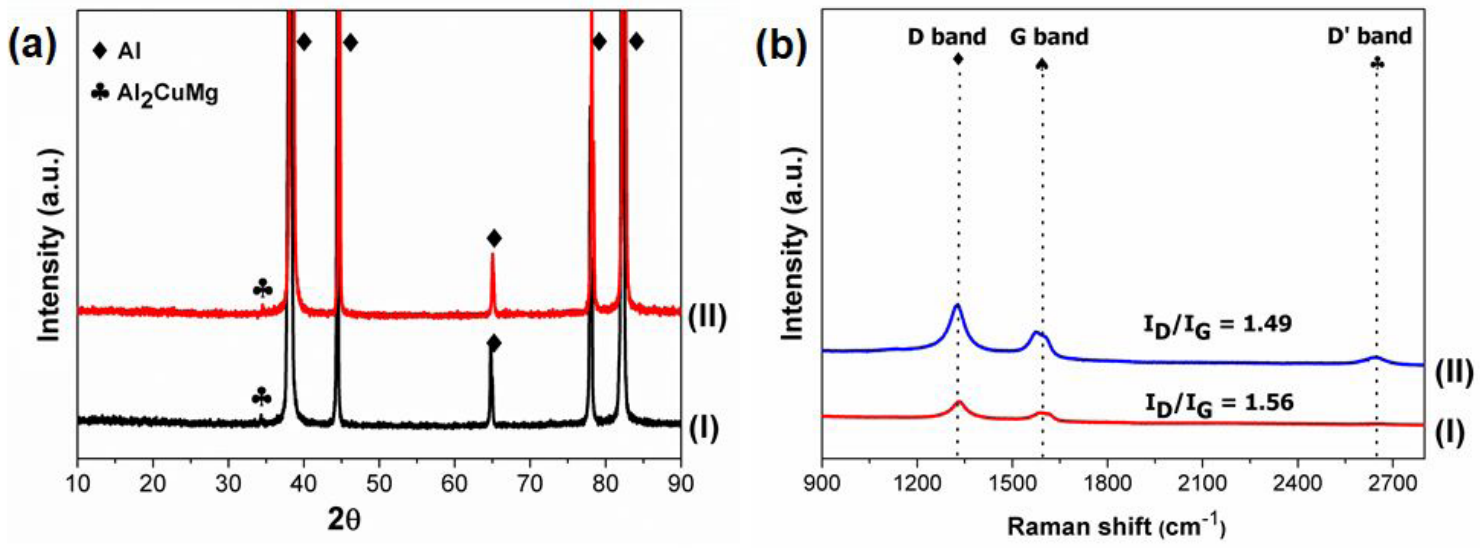

Figure 6. Composite B (a) XRD patterns of the composite (I) as extruded composite without heat treatment, (II) artificial aged composite; and (b) Raman spectra of (I) as hot extruded, (II) after solubilized treatment.

to the small fraction of this phase in composite $\mathrm{B}$, which is not detected by the $\mathrm{x}$-ray diffraction. Figure $6 \mathrm{~b}$ presents the Raman spectra of composite $B$ evidencing the $I_{D} / I_{G}$ intensity ratio. Although Raman analyses for aged composite B were impaired by its high reflectance, the Raman spectra of composite A (Figure 3d) after heat treatment can also support the integrity conservation of the reinforcement of crystalline CNT in this composite too.

Figure 7 exhibits data for the hardness of composites $\mathrm{A}$ and $\mathrm{B}$, as well as for several composites analyzed by other researchers. Composite $\mathrm{A}$ in the as extruded condition presented a hardness $7 \%$ higher than the AA 7075 alloy sintered at $525^{\circ} \mathrm{C}$, and hot extruded at $425^{\circ} \mathrm{C}$, water quenched and presented a hardness value of $81.3 \pm 1.5 \mathrm{HV}^{29}$. The hardness of the aged composite $\mathrm{A}$ is $72 \%$ higher than the as extruded material and $43 \%$ higher than the solubilized condition.

The hardness of the aged Composite A processed by the present powder metallurgy route is equivalent to the AA7050 hardness processed by spray forming (147 HV), which is higher than the hardness of conventionally cast alloy ${ }^{25}$. Also, the hardness of the aged composite $\mathrm{A}$ is equivalent to the sintered and hot extruded 2\% MWCNT/AA7075 composite prepared by Uriza-Vega et al. ${ }^{6}$. It should be noted that their composite underwent a milling process and had an increased strength because of a largest (four times higher) carbon nanotube content, together with hardening of the deformed surface particles due to milling process, and smaller particle size. This situation makes the value of composite A in this study even more expressive.

The higher strength of the aged composite can be associated with age hardening due to the precipitation of the hardening phase $\eta$ ', and due to strengthening with the dispersion of CNT in the AA7050 alloy matrix accomplished by the powder metallurgy route developed in this work. This 0.5 wt. \% MWCNT/AA7050 achieved a hardness similar to

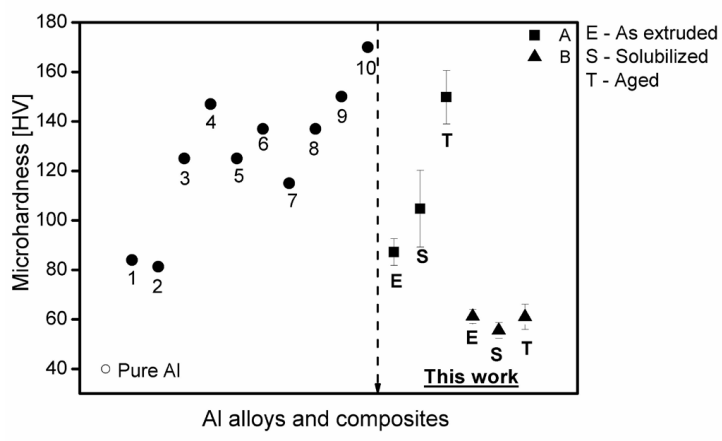

Figure 7. Microhardness comparison of different materials based in $\mathrm{Al}, \mathrm{Al}$ alloys, and composites reinforced by MWCNT. Hardness values of composite $\mathrm{A}$ is represented by the cube symbol, and composite $\mathrm{B}$ is represented by the triangle symbol. References and alloys for the numbered •: Pure Al [3], (1) 1,5\% MWCNT/Al [3], (2) AA7075 by PM [6], (3) AA7075 by PM [29], (4) AA7050 by spray [25], (5) Al-Zn-Mg extruded and aged [36], (6) AA7075 aged [37], (7) 1\% MWCNT/AA6061 [38], (8) 3\% MWCNT/AA6061 [38], (9) 2\% MWCNT/AA7075 [6], (10) 1 wt.\% MWCNT/AA7075 aged [37].

other aged AA7XXX alloys processed by casting ${ }^{25,36}$, and other composites made also by powders, but with a higher amount of carbon nanotubes ${ }^{37,38}$.

Generally, metals reinforced with carbon nanotubes have an increase in mechanical strength through different mechanisms. The main mechanisms discussed in the literature about CNT reinforcement are load transfer ${ }^{39,40}$, Orowan's mechanism ${ }^{1,41}$, and thermal expansion mismatch strengthening ${ }^{9,42}$. It is believed that these mechanisms act simultaneously, since neither single mechanism can explain the increase in the mechanical properties verified in these composites $^{42}$. 
The final strength of composites based in Al alloys reinforced with carbon nanotubes is the sum from contributions of the hardening by the solid solution of the matrix, hardening by precipitation, and the hardening mechanisms that involve the presence of carbon nanotubes $7,39,43$.

Composite $\mathrm{B}$ is $50 \%$ stronger than pure $\mathrm{Al}$ made by powder metallurgy ${ }^{3}$, and did not present a hardness increase after heat treatment due to the absence of enough $\eta$ ' phase precipitation. One possible explanation to the similar values of hardeness found in composite B in the different conditions is related with the small amount of AA7050 inside the composite B. This fact increases the possibility that the hardness indentation interacs more with de pure $\mathrm{Al}$, which is softer that the AA7050. The solubilized sample for composite $\mathrm{A}$ and $\mathrm{B}$ show that the solution heat treatment apparently increases the hardness in composite A and slightly decreases in composite $\mathrm{B}$. The explanation for the composite $\mathrm{A}$ is that the solution heat treatment may have recovered some of the work hardening (or even recrystallized) and solubilized the coarse incoherent precipitation during the extrusion, which impairs the hardness of the material. Regarding the composite $\mathrm{B}$, as the amount of AA7050 is smaller, the effect of the solubilization heat treatment is less pronounced, which kept the hardness almost in the same value as the extruded sample.

\section{Conclusion}

In this paper, two composites were developed by a powder metallurgy route. The first composite (composite A) using the AA7050 alloy and 0.5 wt. $\%$ of MWCNT, and the second (composite B) is a hybrid composite based on Al matrix with the addition of $20 \mathrm{wt} . \%$ of the powder of composite A. The following conclusions can be drawn:

1. The production of the composites by powder metallurgy route shows good adhesion of functionalized MWCNT on the metallic surface, with the occurrence of regions with dispersed MWCNT and others with agglomerated nanotubes;

2. The composite made by AA7050 presents common second-phases of AA7050 heat treated with precipitation of the hardening phase $(\eta ')$ after artificial aging of composite A;

3. The hardness of the composite A aged is $72 \%$ higher than the material as extruded;

4. No difference in hardness was observed in composite $\mathrm{B}$ after heat treatment due to lesser amount of A17050 and carbon nanotubes;

5. Results of Raman spectroscopy indicate that after the consolidation process and heat treatment the MWCNT could have remained in crystalline form although this fact should be addressed in further study.

\section{Acknowledgements}

This work was supported by CAPES, also CNPq and Fapemig. The authors also acknowledge PPGEM-UFMG (Programa de Pós-graduação em Engnharia Metalúrgica, Materiais e de Minas), CAPES-PROEX (Coordenação de Aperfeiçoamento de Pessoal de Nível Superior), and CTNano (Centro de Tecnologia em Nanomateriais e Grafeno) for providing the equipment and technical support for experiments involving carbon nanotubes. Also, we acknowledge to Leonardo Mayer Reis for his assistance with the consolidation process. The authors would like to acknowledge the Center of Mi- croscopy at the Universidade Federal de Minas Gerais (http://www. microscopia.ufmg. br) for providing the equipment and technical support for experiments involving electron microscopy.

\section{References}

1. Thomas S, Umasankar V. Review of recent progress in the development and properties of aluminum metal matrix composites reinforced with multiwalled carbon nanotube by powder metallurgy route. Mater Perform Charact. 2019;8(3):371-400. http://dx.doi.org/10.1520/mpc20180140.

2. Chen B, Kondoh K, Imai H, Umeda J, Takahashi M. Simultaneously enhancing strength and ductility of carbon nanotube/aluminum composites by improving bonding conditions. Scr Mater. 2016;113:158-62. http://dx.doi.org/10.1016/j. scriptamat.2015.11.011.

3. Yang X, Zou T, Shi C, Liu E, He C, Zhao N. Effect of carbon nanotube (CNT) content on the properties of in-situ synthesis CNT reinforced Al composites. Mater Sci Eng A. 2016;660:11 8. http://dx.doi.org/10.1016/j.msea.2016.02.062.

4. Esawi AMK, Morsi K, Sayed A, Taher M, Lanka S. The influence of carbon nanotube (CNT) morphology and diameter on the processing and properties of CNT-reinforced aluminium composites. Compos Part A Appl Sci Manuf. 2011;42(3):23443. http://dx.doi.org/10.1016/j.compositesa.2010.11.008.

5. Jagannatham M, Chandran P, Sankaran S, Haridoss P, Nayan N, Bakshi SR. Tensile properties of carbon nanotubes reinforced aluminum matrix composites: a review. Carbon. 2020;160:14 44. http://dx.doi.org/10.1016/j.carbon.2020.01.007.

6. Uriza-Vega E, Carreño-Gallardo C, López-Meléndez C, Cuadros-Lugo E, Pérez-Bustamante R, Ledezma-Sillas E, Herrera-Ramirez JM. Mechanical behavior of multiwalled carbon nanotube reinforced 7075 aluminum alloy composites prepared by mechanical milling and hot extrusion. Mat Res. 2019;22(2). https://doi.org/10.1590/1980-5373-mr-2018-0652.

7. Xu R, Tan Z, Fan G, Ji G, Xiong D, Guo Q, et al. High-strength $\mathrm{CNT} / \mathrm{Al}-\mathrm{Zn}-\mathrm{Mg}-\mathrm{Cu}$ composites with improved ductility achieved by flake powder metallurgy via elemental alloying. Compos Part A Appl Sci Manuf. 2018;111:1-11. http://dx.doi. org/10.1016/j.compositesa.2018.05.012.

8. Chen B, Li S, Imai H, Jia L, Umeda J, Takahashi M, et al. An approach for homogeneous carbon nanotube dispersion in $\mathrm{Al}$ matrix composites. Mater Des. 2015;72:1-8. http://dx.doi. org/10.1016/j.matdes.2015.02.003.

9. Nam DH, Kim YK, Cha SI, Hong SH. Effect of CNTs on precipitation hardening behavior of $\mathrm{CNT} / \mathrm{Al}-\mathrm{Cu}$ composites. Carbon 2012;50(13):4809-14. http://dx.doi.org/10.1016/j. carbon.2012.06.005.

10. Thomas S, Umasankar V. Effect of MWCNT reinforcement on the precipitation-hardening behavior of AA2219. Int J Miner Metall Mater. 2018;25:53-61.

11. Meng X, Liu T, Shi C, Liu E, He C, Zhao N. Synergistic effect of CNTs reinforcement and precipitation hardening in in-situ CNTs/Al - Cu composites. Mater Sci Eng A. 2015;633:103-11. http://dx.doi.org/10.1016/j.msea.2015.03.007.

12. Shin SE, Choi HJ, Bae DH. Electrical and thermal conductivities of aluminum-based composites containing multi-walled carbon nanotubes. J Compos Mater. 2013;47:2249-56. http://dx.doi. org/10.1177/0021998312456891.

13. Nie JH, Jia CC, Jia X, Li Y, Zhang YF, Liang XB. Fabrication and thermal conductivity of copper matrix composites reinforced by tungsten-coated carbon nanotubes. Int J Miner Metall Mater. 2012;19:446-52. http://dx.doi.org/10.1007/s12613-012-0577-3 
14. Wu J, Zhang H, Zhang Y, Wang X. Mechanical and thermal properties of carbon nanotube/aluminum composites consolidated by spark plasma sintering. Mater Des. 2012;41:344-8. http:// dx.doi.org/10.1016/j.matdes.2012.05.014.

15. Guo B, Chen B, Zhang X, Cen X, Wang X, Song M, et al. Exploring the size effects of Al4C3on the mechanical properties and thermal behaviors of $\mathrm{Al}$ based composites reinforced by $\mathrm{SiC}$ and carbon nanotubes. Carbon. 2018;135:224-35. http:// dx.doi.org/10.1016/j.carbon.2018.04.048.

16. Eid E, Ragab M. Synergetic Reinforcement of Cu-11.0 wt. \% Al Alloy with Al2O 3 nano-sized particles and carbon nanotubes CNTs. Mod Approaches Mater Sci. 2019;2(1):186-94. http:// dx.doi.org/10.32474/MAMS.2019.02.000131.

17. Kim HH, Babu JSS, Kang CG. Hot extrusion of A356 aluminum metal matrix composite with carbon nanotube/A12O3 hybrid reinforcement. Metall Mater Trans. 2014;45:2636-45. http:// dx.doi.org/10.1007/s11661-014-2185-5.

18. Li S, Su Y, Ouyang Q, Zhang D. In-situ carbon nanotube-covered silicon carbide particle reinforced aluminum matrix composites fabricated by powder metallurgy. Mater Lett. 2016;167:118-21. http://dx.doi.org/10.1016/j.matlet.2015.12.155.

19. Saba F, Sajjadi SA, Haddad-Sabzevar M, Zhang F. Exploring the reinforcing effect of TiC and CNT in dual-reinforced Almatrix composites. Diamond Related Materials. 2018;89:180-9. http://dx.doi.org/10.1016/j.diamond.2018.09.007.

20. Morsi K, Esawi AMK, Borah P, Lanka S, Sayed A, Taher M. Properties of single and dual matrix aluminum - carbon nanotube composites processed via spark plasma extrusion (SPE). Mater Sci Eng A. 2010;527(21-22):5686-90. http:// dx.doi.org/10.1016/j.msea.2010.05.081.

21. Salama EI, Abbas A, Esawi AMK. Preparation and properties of dual-matrix carbon nanotube-reinforced aluminum composites. Compos Part A Appl Sci Manuf. 2017;99:84-93. http://dx.doi. org/10.1016/j.compositesa.2017.04.002.

22. Wei H, Li Z, Xiong DB, Tan Z, Fan G, Qin Z, et al. Towards strong and stiff carbon nanotube-reinforced high-strength aluminum alloy composites through a microlaminated architecture design. Scr Mater. 2014;75:30-3. http://dx.doi.org/10.1016/j. scriptamat.2013.11.014

23. Batista LA, Felisberto MD, Silva LS, Cunha THR, Mazzer EM. Influence of multi-walled carbon nanotubes reinforcements on hardness and abrasion behaviour of porous Al-matrix composite processed by cold pressing and sintering. J Alloys Compd. 2019;791:96-9. http://dx.doi.org/10.1016/j.jallcom.2019.03.265.

24. Mazzer EM, Afonso CRM, Galano M, Kiminami CS, Bolfarini C. Microstructure evolution and mechanical properties of Al$\mathrm{Zn}-\mathrm{Mg}-\mathrm{Cu}$ alloy reprocessed by spray-forming and heat treated at peak aged condition. J Alloys Compd. 2013;579:169-73. http://dx.doi.org/10.1016/j.jallcom.2013.06.055.

25. Mazzer EM, Afonso CRM, Bolfarini C, Kiminami CS. Microstructure study of Al 7050 alloy reprocessed by spray forming and hot-extrusion and aged at $121 \mathrm{C}$. Intermetallics. 2013;43:182-7. http://dx.doi.org/10.1016/j.intermet.2013.08.004.

26. Rometsch PA, Zhang Y, Knight S. Heat treatment of 7xxx series aluminium alloys - some recent developments. Trans Nonferrous Met Soc China. 2014;24(7):2003-17. http://dx.doi. org/10.1016/S1003-6326(14)63306-9.

27. Hilding J, Grulke EA, Zhang ZG, Lockwood F. Dispersion of carbon nanotubes in liquids. J Dispers Sci Technol. 2003;24(1):141. http://dx.doi.org/10.1081/DIS-120017941

28. Chen X, Tao J, Liu Y, Bao R, Li F, Li C, et al. Interface interaction and synergistic strengthening behavior in pure copper matrix composites reinforced with functionalized carbon nanotube- graphene hybrids. Carbon. 2019;146:736-55. http://dx.doi. org/10.1016/j.carbon.2019.02.048.

29. Taleghani MAJ, Navas EMR, Torralba JM. Microstructural and mechanical characterisation of 7075 aluminium alloy consolidated from a premixed powder by cold compaction and hot extrusion. Mater Des. 2014;55:674-82. http://dx.doi. org/10.1016/j.matdes.2013.10.028.

30. Xu D, Li Z, Wang G, Li X, Lv X, Zhang Y, et al. Phase transformation and microstructure evolution of an ultrahigh strength $\mathrm{Al}-\mathrm{Zn}-\mathrm{Mg}-\mathrm{Cu}$ alloy during homogenization. Mater Charact. 2017;131:285-97. http://dx.doi.org/10.1016/j. matchar.2017.07.011.

31. Xie F, Yan X, Ding L, Zhang F, Chen S, Chu MG, et al. A study of microstructure and microsegregation of aluminum 7050 alloy. Mater Sci Eng A. 2003;355(1-2):144-53. http://dx.doi. org/10.1016/S0921-5093(03)00056-X.

32. Ma K, Wen H, Hu T, Topping TD, Isheim D, Seidman DN, et al. Mechanical behavior and strengthening mechanisms in ultrafine grain precipitation-strengthened aluminum alloy. Acta Mater. 2014;62:141-55. http://dx.doi.org/10.1016/j.actamat.2013.09.042.

33. Chung T, Yang Y, Shiojiri M, Hsiao C, Li W, Tsao C, et al. An atomic scale structural investigation of nanometre-sized $\eta$ precipitates in the 7050 aluminium alloy. Acta Mater. 2019;174:35168. http://dx.doi.org/10.1016/j.actamat.2019.05.041.

34. Iqbal MW, Singh AK, Iqbal MZ, Eom J. Raman fingerprint of doping due to metal adsorbates on graphene. J Phys Condens Matter. 2012;24:335301. http://dx.doi.org/10.1088/09538984/24/33/335301

35. Trinh P, Luan N, Phuong DD, Minh PN, Weibel A, Mesguich $\mathrm{D}$, et al. Microstructure, microhardness and thermal expansion of CNT/Al composites prepared by flake powder metallurgy. Compos Part A Appl Sci Manuf. 2018;105:126-37. http://dx.doi. org/10.1016/j.compositesa.2017.11.022.

36. Zhang Z, Deng Y, Ye L, Sun L, Xiao T, Guo X. Effect of multi-stage aging treatments on the precipitation and mechanical properties of Al-Zn-Mg alloys. Mater Sci Eng A. 2020;785:139394. http:// dx.doi.org/10.1016/j.msea.2020.139394.

37. Zhang HB, Wang B, Zhang YT, Li Y, He JL, Zhang YF. Influence of aging treatment on the microstructure and mechanical properties of CNTs/7075 Al composites. J Alloys Compd. 2020;814:152357. http://dx.doi.org/10.1016/j.jallcom.2019.152357.

38. Babu JSS, Lee CH, Kang CG. Study of the mechanical and workability properties of extruded aluminium (A16061) based composites reinforced with MWCNTs. J Mater Res Technol. 2020;9(3):5278-5292 https://doi.org/10.1016/j.jmrt.2020.03.054.

39. Anas NS, Dash RK, Rao TN, Vijay R. Effect of carbon nanotubes as reinforcement on the mechanical properties of aluminum-copper- magnesium alloy. J Mater Eng Perform. 2017;26:3376-86. http://dx.doi.org/10.1007/s11665-017-2730-7.

40. Zhou W, Yamamoto G, Fan Y, Kwon H, Hashida T, Kawasaki A. In-situ characterization of interfacial shear strength in multi-walled carbon nanotube reinforced aluminum matrix composites. Carbon. 2016;106:37-47. http://dx.doi.org/10.1016/j. carbon.2016.05.015.

41. Chen B, Shen J, Ye X, Jia L, Li S, Umeda J, et al. Length effect of carbon nanotubes on the strengthening mechanisms in metal matrix composites. Acta Mater. 2017;140:317-25. http://dx.doi. org/10.1016/j.actamat.2017.08.048.

42. Park JG, Keum DH, Lee YH. Strengthening mechanisms in carbon nanotube-reinforced aluminum composites. Carbon. 2015;95:690-8. http://dx.doi.org/10.1016/j.carbon.2015.08.112.

43. Bakshi SR, Agarwal A. An analysis of the factors affecting strengthening in carbon nanotube reinforced aluminum composites. Carbon. 2011;49(2):533-44. http://dx.doi.org/10.1016/j.carbon.2010.09.054. 